\title{
Cornelia de Lange Syndrome with Congenital Glaucoma
}

\section{Vijaya Pai* and Ashish Rander \\ Department of Ophthalmology, Kasturba Medical College, Manipal University, India}

"Corresponding author: Vijaya Pai, Professor, Department of Ophthalmology, Kasturba Medical College, Manipal University, India, Tel: 09845426427; E-mail: paivijaya@yahoo.co.in

Received date: November 26, 2016; Accepted date: January 17, 2017; Published date: January 20, 2017

Copyright: (C) $2017 \mathrm{PH}$ Vijaya, et al. This is an open-access article distributed under the terms of the Creative Commons Attribution License, which permits unrestricted use, distribution, and reproduction in any medium, provided the original author and source are credited.

\begin{abstract}
Cornelia de Lange syndrome is a rare syndrome with distinct facial features, ocular features and genetic abnormality. Glaucoma is a rare ocular association in these patients. We present a case of Cornelia de Lange Syndrome with successfully managed glaucoma with surgery.
\end{abstract}

Keywords: Cornelia de lange syndrome; Congenital glaucoma

\section{Introduction}

Cornelia De Lange syndrome (CDLS), also known as Brachmann de Lange syndrome is a rare syndrome. It is characterised by distinctive facial dysmorphism, growth retardation, developmental delay, upper limb reduction defects, gastroesophageal dysfunction, ophthalmologic and genitourinary anomalies, hirsutism, pyloric stenosis, congenital diaphragmatic hernias, cardiac septal defects, and hearing loss. The syndrome was first described by a Dutch paediatrician named Cornelia de Lange, in 1933 [1].

Though the genetic basis of this syndrome is not clear, a majority of cases are due to spontaneous mutations. The defective gene can be inherited from either parent, making it autosomal dominant type of inheritance [2].

Synophrys, long curled lashes, myopia, and hypertrichosis of the brows. These patients have also been found to have ptosis, epiphora, nasolacrimal duct obstruction, and micro cornea, congenital glaucoma, corneal opacities, iris heterochromia and optic nerve head pallor/atrophy [3].

In this case, we aim to present the rare occurrence of congenital glaucoma among the several other ophthalmic features in a child with Cornelia de Lange syndrome.

\section{Case Report}

An eight month old female child with Cornelia de Lange syndrome with classical facial features was referred to the department of Ophthalmology to rule out glaucoma in view of megalocornea. The mother gave history of intolerance to bright light, chronic watering and discharge from both eyes since birth. History of nocturnal lagophthalmos was present. The baby was the first born child of the couple, born at 35 weeks of gestation by caesarean section. There was no history of consanguinity. There was no family history of similar complaints.

The facial features included microcephaly, synophrys, smooth philtrum, thin upper lip and hirsutism. On examination, the child had pooling of tears in both the eyes, megalocornea (horizontal corneal diameter was $14 \mathrm{~mm} \mathrm{OU}$ ), and central corneal opacity in OU.
Intraocular pressure measured using Perkin's applanation tonometer was Right eye: $8 \mathrm{mmHg}$; Left eye: $9 \mathrm{mmHg}$ under sedation with Triclofos sodium (Pedicloryl, Dr.Reddy's Laboratories Ltd, Dose: 250 $\mathrm{mg} / 2.5 \mathrm{ml}$ ). Retinoscopy with atropine $1 \%$ showed Right eye (OD) compound myopic astigmatism (-6.50 Dcyl sphere and -3.50 Dcyl at $100^{\circ}$ ) and Left eye (OS) myopia of $-11.00 \mathrm{D}$. Fundus examination was normal. A diagnosis of congenital NLDO with congenital myopia was made. Mother was advised lacrimal sac massaging, topical chloramphenicol $0.5 \%$ drops and tobramycin $0.3 \%$ eye ointment at night (Figure 1).

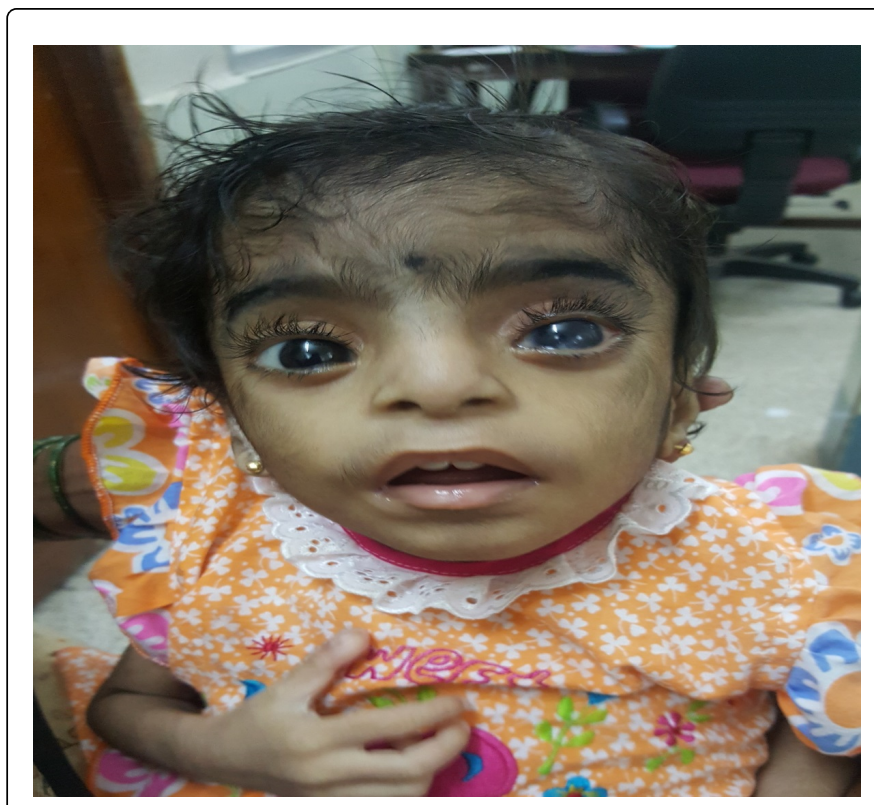

Figure 1: Showing typical facial features. Note the bilateral large cornea.

On review after 1 month, mother reported decrease in watering from the eyes. On examination, corneal opacity was persisting and this time Haab's striae were noted in OU. Intraocular pressure measured using Perkin's applanation tonometer was $22 \mathrm{mmHg}$ and $18 \mathrm{mmHg}$ in OD and OS respectively Fundus examination revealed OU myopic discs. Cup: disc ratio was 0.3 and 0.6 in OD and OU respectively. In 
view of large cornea, Haab's striae, high myopia a diagnosis of congenital glaucoma was made. The child was started on topical dorzolamide $2 \%$ thrice daily and parents were informed about the need for surgery to treat glaucoma. Intraocular pressure on dorzolamide was $18 \mathrm{~mm} \mathrm{Hg}$ in BE on review after 2 weeks.

The child underwent trabeculotomy with trabeculectomy with mitomycin C[MMC], $0.02 \%$ for 2 minutes in the left eye under general anaesthesia. Sac syringing was done before the procedure, and revealed patent lacrimal drainage system on both sides. Same procedure was repeated in the right eye a month later.

On last follow up, two years after the surgery, IOP was under control and there was no progression of myopia.

\section{Discussion}

Cornelia de Lange syndrome is a multiple congenital anomaly syndrome with features varying widely from mild to severe. It is characterized by intrauterine growth retardation, developmental delay, mental retardation, distinctive facial features, respiratory and feeding difficulties, gastroesophageal dysfunction, and cardiac septal defects. Our patient had almost all of these features.

Our patient was the first child born out of a non-consanguineous marriage. The child was born late preterm at 35 weeks of gestation by emergency Caesarean section due to severe oligomnios. The birth weight was $2010 \mathrm{~g}$, length of $44 \mathrm{~cm}$, and head circumference of $32 \mathrm{~cm}$. On head to toe examination, the child had microcephaly, excessive forehead and facial hair, up slant palpebral fissures, low hanging columella, smooth philtrum, thin upper lip, high arched palate, posterior cleft palate, small chin, left low set ears. Echocardiogram revealed Ventricular septal defect with patent ductus arteriosus.

Patients affected with CdLS have been reported to have synophrys (95\%), long lashes (90\%), up slant palpebral fissure (24\%), telecanthus (50\%), hypertelorism (53\%), ptosis (45\%), nystagmus (33\%), strabismus (14\%), myopia (60\%), symptoms of nasolacrimal duct obstruction (59\%) in a study of 22 patients with CdLS by Levin et al. [3]. Other associated features included corneal opacities, micro cornea, iris heterochromia and optic nerve head pallor/atrophy.

Our patient had mild Nasolacrimal duct obstruction (class I) and severe myopia (class II) according to the Ophthalmologic Phenotype Classifications by Nallasamy et al. in their study to evaluate genotypephenotype correlations with regard to severity of ophthalmologic findings in CdLS patients [4].

The mother reported symptoms of watering and discharge from both eyes in the child since birth suggestive of Nasolacrimal duct obstruction. Normal IOP, with myopia, large cornea misled us to the diagnosis of congenital NSLDO.

On follow up Haab's striae were noted. Even then IOP was not very high. In view of Haab's striae, high myopia, marginally raised IOP in both the eyes, a diagnosis of congenital glaucoma was made and was managed successfully by trabeculectomy with trabeculotomy with MMC.

Geneticist was consulted and karyotyping done revealed additional material on chromosome 11 (de novo), parental karyotyping was normal. Chromosomal microarray analysis (CMA) showed duplication at cytoband $3 \mathrm{q}$ and deletion at cytoband 11q.

The characteristic facial features, other physical features and presence of the de novo mutation led to the diagnosis of Cornelia de Lange syndrome.

Cornelia de Lange syndrome can result from mutations in at least five genes: NIPBL, SMC1A, HDAC8, RAD21, and SMC3. Mutations in the NIPBL gene have been identified in more than half of all people with this condition; mutations in the other genes are much less common [2].

Cornelia de Lange syndrome (CdLS) can be inherited in an autosomal dominant (NIPBL, SMC2, or RAD21) or X-linked (SMC1A or HDAC8) manner depending on the underlying genetic cause. However, most cases (more than 99\%) result from new (de novo) mutations and occur in people with no family history of the condition $[5,6]$.

In our patient, also there was no positive family history. There are only three reported cases of congenital glaucoma in a child with CdLS. Lee and Brandt et al reported a case of congenital glaucoma in association with aniridia which was treated by Ahmed glaucoma valve [7]. The other two cases of congenital glaucoma were described by Nallaswamy et al. which had normal iris [4].

\section{Conclusion}

Diagnosis of CdLS depends on the characteristic facial features and physical features. Initial normal IOP with watery eyes misled us to diagnosis of congenital NLDO. With the appearance of Haab's striae a diagnosis of congenital glaucoma was made though the IOP was not very high. This again highlights the importance of the fact that, high myopia in a child should alert the physician towards the possibility of congenital glaucoma. So far only three cases of CdLS with congenital glaucoma have been reported in literature. The knowledge of the key findings associated with CdLS combined with proper follow up can minimize complications.

\section{References}

1. De Lange C (1933) Sur un type nouveau de degenerescence (typus Amstelodamensis). Arch Med Enfants 36: 713-719.

2. Cornelia de Lange syndrome - Genetics Home Reference, 2015.

3. Levin AV, Seidman DJ, Nelson LB, Jackson LG (1990) Ophthalmologic findings in the Cornelia de Lange syndrome. J Pediatr Ophthalmol Strabismus 27: 94-102.

4. Nallasamy S, Kherani F, Yaeger D, McCallum J, Kaur M, et al. (2006) Ophthalmologic Findings in Cornelia de Lange Syndrome- A GenotypePhenotype Correlation Study. Arch Ophthalmol 24: 552-557.

5. Deardorff MA, Clark DM, Krantz ID (2016) Cornelia de Lange Syndrome. Gene Rev.

6. Mustafa Tekin (2015) Cornelia De Lange Syndrome. Medscape Ref.

7. Lee WB, Brandt JD, Mannis MJ, Huang CQ, Rabin GJ (2003) Aniridia and Brachmann-de Lange syndrome. Cornea 22: 178-180. 